\title{
Percent Inflammatory Marker Positive
}

National Cancer Institute

\section{Source}

National Cancer Institute. Percent Inflammatory Marker Positive. NCI Thesaurus. Code C159479.

A quantitative measurement of the percent of a sample that is positive for inflammatory markers, including the presence of capillary dilatation, edema and increased leukocytes. 